\title{
MARCADAS PELA COR E PELA HONRA: REPENSANDO O PÓS-ABOLIÇÃO EM MINAS GERAIS A PARTIR DAS EXPERIÊNCIAS DE LIBERDADE DE MULHERES NEGRAS
}

\author{
Cleudiza Fernandes de Souza'
}

\begin{abstract}
Resumo
Vigorou por anos na historiografia uma ideia de passividade da população negra em relação ao processo abolicionista em Minas Gerais e inexistência de projetos políticos contrários à escravidão. $\mathrm{O}$ objetivo deste trabalho é oferecer uma leitura crítica a essa concepção, propondo demonstrar, a partir da expansão da noção de atuação social, que as atuações das camadas populacionais foram presentes e heterogêneas, no período escravista e pós-emancipação. Para sustentar tal argumentação, analisaremos enquanto fontes principais processos criminais envolvendo ex-escravas, no período pós-abolição na cidade mineira de Oliveira. As informações ali contidas podem revelar aspectos sobre as experiências de liberdade de mulheres negras. Artigos da imprensa conservadora da época também serão usados para cruzar informações e demonstrar a presença da variedade de posições.
\end{abstract}

Palavras chaves: Gênero, Raça, Justiça.

\begin{abstract}
For years, the historiography held an idea of the passivity of the black population in relation to the abolitionist process in Minas Gerais and the absence of political projects against slavery. The objective of this work is to offer a critical reading to this conception, proposing to demonstrate, from the expansion of the notion of social performance, that the actions of the popular layers were present and heterogeneous, in the slavery and postemancipation period. We will analyze as main sources criminal cases involving ex-female slaves, in the post-abolition period in the town of Oliveira, Minas Gerais, to support such an argument. The information contained may reveal aspects of black women's freedom experiences. We will use articles from the conservative press of the time to crosscheck information and demonstrate the presence of the variety of positions.
\end{abstract}

Keywords: Gender, Race, Justice.

\footnotetext{
${ }^{1}$ Doutoranda em História Social na Universidade Federal do Rio de Janeiro. Mestra e Graduada em História pela Universidade Federal de São João del-Rei. Bolsista financiada pela Coordenação de Aperfeiçoamento de Pessoal de Nível Superior (CAPES). E-mail para contato: cleosouzalh@gmail.com
} 
O periódico Gazeta de Oliveira era o veículo informativo de maior circulação na cidade interiorana de Oliveira, no contexto da virada do século XIX para o XX. Era direcionado principalmente às camadas de fazendeiros e elites abastadas daquele município. Em suas páginas, eram múltiplos os artigos contendo posições favoráveis aos proprietários de escravos, na guerra política que se consolidou no país ainda nos anos de derrocada da escravidão. Nos anos iniciais do pós-emancipação, não foi muito diferente. A preocupação agora era estabelecer a ordem nas lavouras e sobre o trabalho dos exescravos, para incentivar a estabilidade agrária dos fazendeiros e evitar possíveis motins entre os trabalhadores negros. ${ }^{2}$ Além desses eixos, o jornal explicitava, em seus artigos literários, representações daquilo que seus escritores e leitores entendiam sobre a imagem do negro, como nesse conto publicado em seis de novembro de 1898, que trata especificamente da questão da mulher negra:

\begin{abstract}
Descia para a mata um grande comboio de escravos, entre os quais sobressaía, por seu porte airoso, olhar sereno mais tristonho, garbos senhoris mas modestos, mantendo sempre a distância por sua nobreza de caráter, por seu procedimento sublime a própria brutalidade de seus condutores um tanto domesticada pela pureza da escrava, uma linda rapariga. ${ }^{3}$
\end{abstract}

O texto "Por bem fazer, mal haver" escrito pelo literato Carmo Gama, denota o tipo de representação em relação à mulher negra que incidia naquele meio social no município. Resumidamente, o conto traz em suas linhas o caso da escrava Margarida, descrita pelo autor como "uma rapariguinha, mulata, dotada dos mais invejáveis predicados". 4 Por se sobressair artisticamente - em outras palavras, tocar "audaciosamente" o piano de sua senhora - a mesma é levada ao lado de outros cativos para longe de sua fazenda de origem, onde deveria ser vendida. Isso tudo como castigo pela petulância em utilizar o instrumento musical da sinhá.

No texto publicado no jornal, as características corporais da escrava são realçadas, algo muito corriqueiro na literatura brasileira na época, em consonância com os discursos científicos. Essa representação parece criar e reforçar não somente trejeitos de sexualização sobre este indivíduo, mas muitas vezes a descrição da falta de supostas

\footnotetext{
${ }^{2}$ Há uma discussão mais detalhada sobre os posicionamentos do referido jornal na virada da escravidão para a abolição em nosso trabalho: SOUZA, Cleudiza Fernandes de. O pós-abolição a partir de perspectivas de gênero e raça: processos criminais envolvendo ex-escravas em Oliveira, Minas Gerais (1890-1905). 2019, 179 p. Dissertação (Mestrado em História) Programa de Pós-graduação em História da Universidade Federal de São João del Rei, São João del-Rei.

${ }^{3}$ GAMA, Carmo. "Por bem fazer, mal haver". Gazeta de Oliveira, 1898, Edição 698, p. 2.

${ }^{4}$ GAMA, Carmo. Gazeta de Oliveira, p. 2.
} 
sensibilidades mais acuradas. ${ }^{5}$ Além da descrição corporal exacerbada, o autor distingue Margarida em relação ao restante do grupo de escravos. Em suas palavras, mantinha “sempre a distância por sua nobreza de caráter", se sobressaindo aos outros cativos, com seus "garbos senhoris, mas modestos". Nas frases transcritas, ao mesmo tempo que "exalta" a figura da negra, o escritor acaba por utilizar figuras depreciativas para julgar a população afrodescendente com pressupostos de inferioridade, ao dizer que suas qualidades só ocorrem porque ela se difere do grupo. Estas características parecem assemelhar-se a uma espécie de herança de literatura naturalista, na qual homens e mulheres negras eram colocados como figuras selvagens e animalescas. ${ }^{6}$

Mas essa "exaltação" não era garantia de uma real apreciação ou de melhores condições na vida dessas mulheres. ${ }^{7}$ A própria personagem não teve um final feliz: foi vendida longe de seu local oriundo. Pagou caro pelos seus "encantos". Além disso, o estereótipo da docilidade ali figurado representava falsamente as subjetividades de mulheres negras, demonstrando apenas imagens construídas e disseminadas pelas elites.

A coluna "Echos", também de 1898, traz no jornal outra textualidade retratando as afrodescendentes. O artigo, que se inicia com os dizeres "pensamento de uma filósofa", e sem assinatura, faz uma descrição estética da imagem feminina da época, centrada na questão dos cabelos:

As mulheres que tem cabelo liso botam papelotes para encrespá-lo, as que tem raça de mulata cansam de alisá-lo: mas as crioulas que tem cabelo carapinhado, para quê o que fazem trancinha à direita, trancinha à esquerda, deixando uns regos escuros à mostra no casco da cabeça? ${ }^{8}$

Os hábitos e aparência de mulheres de pele mais escura, ou "crioulas", são questionados no testilho publicado na coluna, também sem assinatura. Martha Abreu constata que canções populares dos séculos XIX e XX reproduziam essa premissa, de enaltecimento da beleza mulata (como no artigo descrito) e depreciação da imagem da negra. ${ }^{9}$ Esse argumento era encaixado dentro de discursos elitistas, no pós-abolição, de

${ }^{5}$ DUARTE, Eduardo de Assis. "Mulheres marcadas: literatura, gênero, etnicidade". SCRIPTA, Belo Horizonte, v. 13, $2^{\circ}$ sem, n .25, 2009, pp. 63-78.

${ }^{6}$ XAVIER, Giovana. "Entre personagens, tipologias e rótulos da 'diferença': a mulher escrava na ficção do Rio de Janeiro no século XIX”. In: GOMES, Flávio; FARIAS, Juliana Barreto; XAVIER, Giovana (orgs.). Mulheres negras no Brasil escravista e no pós-emancipação. São Paulo: Selo Negro, 2012, p.70.

${ }^{7}$ XAVIER, Giovana. In: GOMES, Flávio; FARIAS, Juliana Barreto; XAVIER, Giovana (orgs.). Mulheres negras no Brasil escravista e no pós-emancipação, p. 80.

${ }^{8}$ Autor desconhecido. "Coluna Echos". Gazeta de Oliveira, Edição 549, 1898, p. 1.

${ }^{9}$ ABREU, Martha Campos. "Sobre mulatas orgulhosas e crioulos atrevidos: conflitos raciais, gênero e nação nas canções populares (Sudeste do Brasil, 1890-1920)". Tempo, n 16, Rio de Janeiro, pp. 143-173. 
elogios à mestiçagem, e de certa forma, de um esperado processo de embranquecimento populacional.

Outra questão que devemos pontuar é que neste jornal em específico não notamos a presença de mulheres escrevendo em colunas, pelo menos não nos artigos que analisamos. Talvez o último texto, contendo o título "pensamento de uma filósofa" possa indicar que a escritora fosse uma mulher, porém, na falta de assinaturas, melhor não afirmar. Além da questão dos estereótipos de gênero e raça, estes, no folhetim, pareciam ser em suma reiterados e criados por figuras masculinas. Afinal, devemos nos lembrar que para a época a ausência de mulheres escrevendo nesses veículos comunicativos era algo corriqueiro. As páginas da Gazeta de Oliveira acabam por seguir um modelo muito usual na época, de objetificação dos corpos femininos negros.

Por outro lado, acaba perdendo de vista as reais potencialidades desses indivíduos, que, não diziam respeito, nem de perto, aos estereótipos como estes aqui transcritos. Segundo Xavier, para além de trabalhar os processos de criação dessas imagens, é preciso historicizar as tipologias pelas quais mulheres negras foram enquadradas: "nessa direção, a articulação entre raça, gênero e sexualidade deve ser entendida como palco privilegiado para a percepção dos conflitos sociais dentro do movimento da história"10.

A partir dos casos judiciais a seguir, também ocorridos em Oliveira, Minas Gerais, no contexto do pós-abolição, veremos que os percalços seguidos por aquelas mulheres eram variados e que estas vivenciaram conflitos que fugiam da percepção advinda das elites. Houve diversas maneiras de atuarem socialmente e lutarem por sua sobrevivência, ultrapassando as fronteiras delineadas e esperadas pelas classes abastadas. A ação da mulher negra ex-escravizada ia contra os pressupostos de passividade retratados pela imprensa, literatura e nichos elitistas.

Os estereótipos criados, inclusive, iam ao encontro de uma concepção tradicional sobre a região, que acabou por reiterar por tempos essa imagem de permissividade. Oiliam José realçou que apesar da Província ter se unido timidamente à campanha da abolição, Minas Gerais se manteve em suma afastada da arena de luta. O autor realçou uma certa pacatez no processo de abolição mineiro, abordando que naquele local ela teria ocorrido de forma mais harmoniosa devido à presença de um núcleo homogêneo conservador e escravista no estado e a falta de fortes campanhas abolicionistas. Nas palavras do autor:

\footnotetext{
${ }^{10}$ XAVIER, Giovana. In: GOMES, Flávio; FARIAS, Juliana Barreto; XAVIER, Giovana (orgs.). Mulheres negras no Brasil escravista e no pós-emancipação, p.82.
} 
Somente através de ações isoladas fizeram sentir os mineiros que também aqui se condenava a supressão da liberdade dos africanos e se trabalhava pela alforria do homem negro. Era talvez a confirmação de que os povos destas montanhas preferirem pensar e agir silenciosamente, mesmo quando os brasileiros de outras plagas levantam alto as vozes de seus pronunciamentos. ${ }^{11}$

Em um panorama nacional, o argumento do Oiliam parecia acompanhar as construções teóricas contemporâneas a seu tempo. Por mais que tenham revolucionado o campo sobre estudos sobre escravidão no Brasil, os importantes trabalhos trazidos pela Escola Sociológica Paulista acabaram por fazer uma leitura estrutural das relações sociais no país e por se centrarem na violência sofrida pelos escravizados, e não sem suas ações práticas de sobrevivência. ${ }^{12}$ Isso, de certa maneira, também contribuiu para a consolidação de uma ideia de que a abolição em território nacional teria sido feita de forma consensual pelas elites, sem participação popular.

Segundo Juliano Custódio Sobrinho, o "mito da mineiridade", que colocaria Minas numa posição de ordem eminente, nada mais era que um projeto político desenhado para a Província, e reiterado por anos por parte da historiografia. ${ }^{13} \mathrm{O}$ autor notou que nessa região, além daqueles que se utilizaram de medidas emancipadoras e mais tímidas, havia indivíduos que extrapolaram as medidas legais para a conquista da liberdade. ${ }^{14}$ É neste sentido, dos múltiplos posicionamentos, que estivera o caráter do processo abolicionista mineiro, que diferentemente da percepção de autores como Oiliam José, ultrapassava as formas conservadoras e fluídas por suposta pacatez.

Outro problema que podemos elencar e que contribuiu para a construção da leitura da passividade é de ordem numérica: havia, até pouco tempo, escassos trabalhos abordando a virada para a abolição em Minas Gerais e os seus primeiros anos pósemancipação, tendo esse processo como recorte. As pesquisas estavam em suma centradas no setecentos e na primeira metade do oitocentos mineiro. Todavia, a multiplicidade de características sociais e históricas percebidas nesses trabalhos para Minas Gerais já poderiam indicar que seria impossível concebermos uma homogeneidade

\footnotetext{
${ }^{11}$ JOSÉ, Oiliam. A Abolição em Minas. Belo Horizonte: Itatiaia, 1962, p. 9.

${ }^{12}$ Ver trabalhos como CARDOSO, Fernando Henrique. Capitalismo e escravidão no Brasil Meridional: o negro na sociedade escravocrata do Rio Grande do Sul. $2^{a}$ edição. São Paulo: Paz e Terra, 1962; e FERNANDES, Florestan. A integração do negro na sociedade de classes. São Paulo: Dominus Editora, $2^{\mathrm{a}}$ edição, 1965.

${ }^{13}$ SOBRINHO, Juliano Custódio. Sobre um tempo de incertezas: o processo de abolição e os significados de liberdade em Minas Gerais (1880-1888). 2014, 293 p. Tese (Doutorado em História). Universidade de São Paulo, Faculdade de Filosofia, Letras e Ciências Humanas. São Paulo, p. 276.

${ }^{14}$ SOBRINHO, Juliano Custódio. Sobre um tempo de incertezas, p. 277.
} 
de posições no processo da abolição entre os dirigentes políticos e ausência de ação entre as camadas negras.

Neste sentido, é cada vez mais necessário expandir a visualização em relação às práticas sociais, indo ao universo de sujeitos comuns, que apesar de estarem externos ao âmbito político formal, mobilizaram formas diversas de ação. Os processos criminais onde as ex-escravizadas estiveram envolvidas são exemplos que oferecem pistas sobre suas trajetórias e como estas podem quebrar as antigas imagens de docilidade e mesmo paternalismo, elucidando outras possibilidades históricas. Veremos que suas experiências de liberdade cruzavam-se aos significados dos crimes em que estavam arroladas. E mais que isso: que as potencialidades de mobilização social podiam se expressar de formas variadas e autônomas em relação ao imaginário concebido pelas elites e por parte da historiografia tradicional sobre Minas.

\section{Mulheres de cor: liberdade, gênero e defesa da honra}

Crimes violentos, envolvendo defesa da honra, apareciam como recorrentes em Minas Gerais ao longo dos séculos XVIII e XIX ${ }^{15}$. A luta pela imagem moral e reputação refletia-se em disputas do cotidiano, onde a população tentava, por meio de acertos de contas, resolver suas pendências. Aspectos de uma sociedade interiorana, onde a violência estava intrínseca às relações sociais. Edna Resende constatou que a violência presente no interior mineiro não era um fator patológico da sociedade, e sim uma moeda de troca legitimada pela população, no momento de resolução de conflitos. ${ }^{16}$

Minas Gerais experimentava, ao longo do XIX, a recente experiência da urbanização, onde a Justiça começava a se enraizar, em meio a alta incidência de crimes de cunho violento ${ }^{17}$. A instituição jurídica tentara então, por um viés civilizador, implantar uma demanda de ordem social na Província ${ }^{18}$. Ao longo do século, percebe-se então uma queda no padrão de violência, devido a mudanças de valor cultural e ação pedagógica do Estado. ${ }^{19}$ Mas a violência ainda estava presente, mesmo que em menores números.

No final do XIX, a âmbito nacional, o Código Penal de 1890 era introduzido. Sua implementação tentava acompanhar os pressupostos de igualdade trazidos pela República

\footnotetext{
${ }^{15}$ VELLASCO, Ivan de Andrade. As seduções da ordem: Violência, criminalidade e administração da Justiça. Minas Gerais, século 19. Bauru, SP: EDUSC. São Paulo: ANPOCS, 2004, p. 169.

${ }^{16}$ RESENDE, Edna Maria. Entre a solidariedade e a violência: valores, comportamentos e a lei em São João del-Rei (1840-1860). São Paulo: Annablume, 2008, p. 105.

${ }^{17}$ VELLASCO, Ivan de Andrade. As seduções da ordem, p. 190.

${ }^{18}$ VELLASCO, Ivan de Andrade. As seduções da ordem, p. 190.

${ }^{19}$ VELLASCO, Ivan de Andrade. As seduções da ordem, p. 292-295.
} 
e pela recente abolição. Mas na prática, o Código continuava reproduzindo problemas anteriores, de tutela a alguns sujeitos da sociedade e perseguição a outros. ${ }^{20}$ Manifestações culturais como a Capoeira e expressões religiosas negras entram em proibição, demonstrando em algumas linhas que apesar de avanços em outros aspectos, o Código ainda guardava e reproduzia pressupostos de criminalização racial.

A nova legislação também reforçava a proteção legislativa sobre o corpo da mulher e contenção dos padrões sexuais. ${ }^{21} \mathrm{O}$ peso moral vigilante expressava-se na forma como alguns casos judiciais foram dirigidos. A situação a seguir, ocorrida no município mineiro de Oliveira em 1893 envolvendo Bárbara, uma ex-escrava idosa, nos oferecerá algumas possibilidades de análise de cruzamento das categorias de gênero e raça com as formas da lei:

\begin{abstract}
A noite do dia três de setembro do corrente ano, às dez horas da noite mais ou menos, o denunciado Simião Nogueira, em companhia de Miceno Raphael, Antônio Cassarola e Francisco Fidélix, dirigiram-se para a casa de Rosaura e Cândida, netas de Bárbara, aí chegando bateram a porta e como não fora aberta, Simião saltou a cerca, arrombou uma janela e penetrou dentro da casa; como Bárbara, indignada, tal viu com tal procedimento, (...) resultando em trocas de palavras insultosas, que tiveram como resultado Simião tomado de um cacete e com ele feito em Bárbara os graves ferimentos do auto do corpo de delicto. Francisco Fidelix que tentou inferir em socorro de Bárbara, censurando o procedimento do denunciado, também foi atingido pelo instrumento contundente vibrado por mãos do denunciado, resultando no paciente os ferimentos constantes do auto do corpo de delito. ${ }^{22}$
\end{abstract}

Na leitura cuidadosa do processo, aparecem duas versões sobre Francisco Fidélix: uma, em que ele seria apenas o vizinho que prestou socorro à vítima. A segunda versão levantada por algumas testemunhas é que Fidélix fazia parte do grupo de rapazes, mas que acabou entrando em conflito com Simião. Mas o que fica claro é que naquela noite do dia 3 de setembro de 1893, Simião Nogueira, Miceno Raphael e Antônio Cassarola teriam se dirigido, num lugar denominado São Bento - Distrito de Cláudio, Oliveira - à casa de duas mulheres chamadas Rosaura e Cândida. Durante a chegada dos mesmos, a avó das duas jovens, Bárbara Francisca de Jesus, estaria dormindo e adoentada. Após a mesma ter dito às netas que não eram horas de "se abrir as portas" para os homens citados,

\footnotetext{
${ }^{20}$ ALVAREZ, Marcos César; SALLA, Fernando; SOUZA, Luiz Antônio F. "A sociedade e a lei: O Código Penal de 1890 e as novas tendências Penais na Primeira República”. Justiça e História. Porto Alegre: v. 3, n. 6, 2003, p. 10.

${ }^{21}$ FAUSTO, Bóris. Crime e cotidiano: A criminalidade em São Paulo, 1880 - 1924. São Paulo: Editora Brasiliense, 1984, p. 195.

${ }^{22}$ Acervo da Comarca do Rio das Mortes: Laboratório de Conservação e Pesquisa Documental da UFSJ (LABDOC/UFSJ). Localização: PC 710, CX. 32. Processo criminal. 1893, p. 2.
} 
inicia-se uma discussão entre ela e Simião. ${ }^{23}$ Os resultados foram agressões a cassetadas dadas por Nogueira e sofridas pela idosa e por Francisco Fidélix, que teria ouvido os gritos e tentado ajudá-la.

Segundo Miceno, ele e os outros dois rapazes teriam se dirigido à casa de Rosaura e Cândida, suas velhas conhecidas, para "passear". ${ }^{24}$ Ao que avistaram as portas fechadas, Simião teria pulado a cerca e ido até a entrada do quintal chamá-las. Foi quando Rosaura abriu a porta que toda a confusão teria se iniciado. Após Simião ter dito palavras injuriosas à jovem, a avó teria dito "que àquelas horas não se devia ter aberto portas". Simião então retrucou, a chamando de "manquinha"; e a ex-cativa respondeu que "manquinha eram os cornos que o amassaram". Foi aí que Simião teria adentrado ao quarto de Bárbara e a espancado utilizando-se de um porrete. Ao escutar os gritos da confusão, o vizinho Francisco Fidélix entra e tenta impedir a ofensa física, recebendo três porretadas. Logo depois, o grupo teria se dispersado.

Segundo umas das testemunhas, Antônio Symplicio Alves de Araújo, lavrador e morador do distrito, Simião manteria relações "ilícitas" com Cândida, e Miceno com Rosaura. ${ }^{25} \mathrm{O}$ "ilícito" aqui faz referência ao fato dos dois homens, tanto Simião, quanto Miceno, serem casados, fato inclusive que os dois confirmam durante os colhimentos de informações dos envolvidos. Legalmente, no Código Penal de 1890, só a mulher poderia receber punição pelo crime de adultério, podendo sofrer até três anos de prisão celular se fosse provado o caso. ${ }^{26} \mathrm{O}$ Código reitera as formas de como o Estado sempre lidara com a questão até então. O homem adúltero só era punido pelo crime caso tivesse uma concubina "teúda ou manteúda", ou seja, se mantivesse financeiramente sua amante, não figurando a ocasião apenas como uma situação passageira. ${ }^{27}$ Esse direcionamento de

\footnotetext{
${ }^{23}$ Acervo da Comarca do Rio das Mortes: Laboratório de Conservação e Pesquisa Documental da UFSJ (LABDOC/UFSJ). Localização: PC 710, CX. 32. Processo criminal. 1893. Depoimento de Francisco Fidélix Rodrigues.

${ }^{24}$ Acervo da Comarca do Rio das Mortes: Laboratório de Conservação e Pesquisa Documental da UFSJ (LABDOC/UFSJ). Localização: PC 710, CX. 32. Processo criminal. 1893. Depoimento de Miceno Rafael Ribeiro.

${ }^{25}$ Acervo da Comarca do Rio das Mortes: Laboratório de Conservação e Pesquisa Documental da UFSJ (LABDOC/UFSJ). Localização: PC 710, CX. 32. Processo criminal. 1893. Depoimento de Antônio Symplicio Alves de Araújo.

${ }^{26}$ BRASIL. Código Penal dos Estados Unidos do Brazil . Artigo 279. Decreto n ${ }^{\circ} 847$, de 11 de outubro de 1890. Disponível em:<https://www2.camara.leg.br/legin/fed/decret/1824-1899/decreto-847-11-outubro1890-503086-norma-pe.html>. Acesso em 22/04/2020.

${ }^{27}$ BRASIL. Código Penal dos Estados Unidos do Brazil. Decreto n ${ }^{\circ} 847$, de 11 de outubro de 1890. Artigo 279, Parágrafo 1. Disponível em:<https://www2.camara.leg.br/legin/fed/decret/1824-1899/decreto-84711-outubro-1890-503086-norma-pe.html>. Acesso em 22/04/2020.
} 
diferenciação de gênero era tanto uma realidade que no exemplo presente o crime de adultério nem sequer é citado ou denunciado pela Promotoria de Justiça.

Mas e se as adúlteras fossem Rosaura e Cândida? Não sabemos como o caso se procederia, porque há também uma variável em relação aos valores morais locais que influenciava as decisões do judiciário. Mas em termos práticos e legais teriam maior possibilidade de serem punidas, visto que enquanto mulheres, só precisariam estar casadas e ter a relação extraconjugal provada. Segundo Rachel Soihet, a tradição da punição do adultério, herdada legalmente desde a Colônia, "representava os riscos da participação de um bastardo na partilha dos bens e na gestão dos capitais". ${ }^{28}$ Ou seja, o homem poderia expressar sua liberdade sexual desde que não atingisse seu patrimônio; ao contrário da mulher, que no ato da traição era lida como "um ser acometido por um desvario momentâneo". ${ }^{29}$ Tal exemplo é interessante para se perceber como os papéis e lugares de gênero são social e historicamente construídos dentro das leis. Por outro lado, a leitura da informalidade feita pelas elites em relação a arranjos de determinados relacionamentos poderia se divergir daquilo que era entendido como legítimo pelas camadas populares. Não que casos ilícitos estivessem presentes apenas entre os pobres. Mas as formas de julgamento e construção moral eram diferenciadas.

Cândida e Rosaura, com idades respectivamente de 25 e 20 anos, apresentaram praticamente a mesma versão à Justiça: que teriam acordado assustadas com o barulho da briga entre Simião e Bárbara. Porém, o que pode ser notado nos relatos é que as mesmas teriam aberto as portas à Simião, Miceno e Antônio, após o primeiro ter saltado a cerca de sua residência. Aparentemente a relação entre elas e os rapazes era consentida, mas as mesmas não citaram isso durante o processo. Recordemos das considerações de Edward Thompson. Ao analisar as antigas vendas de esposas na Inglaterra no século XVIII e XIX, o historiador percebeu que aqueles procedimentos, que até então poderiam ser lidos como aberrações, eram na verdade consentidos, entre homens e mulheres. Como o divórcio era algo de difícil acesso entre os pobres, dada a burocracia religiosa e de valores da época, a venda da esposa - geralmente combinada e feita para um amante ou familiar da mesma - era a forma mais prática do casal se abdicar de um casamento infeliz. Porém, sofrendo

\footnotetext{
${ }^{28}$ SOIHET, Rachel. Mulheres pobres e violência no Brasil urbano. In: PRIORI, Mary Del (org.). História das Mulheres no Brasil. São Paulo: Contexto, 2004, p 319.

${ }^{29}$ SOIHET, Rachel. In: PRIORI, Mary Del (org.). História das Mulheres no Brasil, p. 382.
} 
menos julgamento e empecilhos morais, já que o processo estava dentro das formalidades das leis. ${ }^{30}$

Muito provavelmente a ausência da afirmação de uma relação ilícita perante o júri foi usada como estratégia, porque em situações penais como essas, muitas vezes as mulheres eram vistas ao mesmo tempo como vítimas e incitadoras do crime. ${ }^{31}$ Não sendo apenas uma expressão de dominação, o processo criminal não deve ser lido meramente como uma ferramenta imposta "de cima para baixo". ${ }^{32}$ Por mais que o Estado seja o grande porta-voz de poder, todos os envolvidos participam na arena de luta à sua maneira, acionando os melhores argumentos e podendo modificar informações quando e se necessário. E como Thomspon nos chama a atenção, mulheres pobres - e nesse caso, negras - também eram agentes de sua própria história, e usavam as ferramentas que podiam para conquista de seus espaços. Apesar dos limites sociais. ${ }^{33}$

O próximo trecho, o depoimento de Rosaura, é um dos raros casos em que o depoimento das mulheres envolvidas aparece. Ausência essa que de certa forma nos diz sobre a forma como a Justiça levara seus procedimentos à frente em relação ao diferenciador de gênero:

Rosaura Maria de Jesus, de idade de vinte anos, fiandeira e costureira, solteira, natural e moradora desse Distrito, aos costumes disse ser neta de Bárbara (ofendida), testemunha informante a quem o juiz não deferiu juramento, mas que prometeu dizer a verdade, do que soubesse e lhe fosse perguntado. E sendo inquirida sobre o fato constante da parte oficial o Juiz, respondeu que das dez para as onze horas da noite do dia três de setembro acordou sobressaltada com as pancadas que Simião dava em sua avó Bárbara, querendo acudi-la foi ameaçada por Simião com uma faca, ao que ela testemunha gritou por Francisco Fidelix gritou para acudi-la. Entrando esse com Antônio Cassarola, Simião deu em Fidelix três porretadas. Contou-lhe depois que o intento do grupo composto de Simião, Miceno, Cassarola e Fidelix era dançar, seguindo-se alteração entre Simião e avó dela testemunha por causa da abertura da porta que fora arrombada por Simião. Perguntada sobre o procedimento de Simião e Bárbara? Disse que o de Simião é mau, e de Bárbara, bom. ${ }^{34}$

Bárbara não teve pronunciamento oficial. Mas foi durante o exame de corpo de delito da mesma, que percebemos seu passado cativo. Mais precisamente "ex-escrava de

\footnotetext{
${ }^{30}$ THOMPSON; E. P. Costumes em comum: estudos sobre a cultura popular tradicional. São Paulo: Companhia das Letras, 1988.

${ }^{31}$ ESTEVES, Martha de Abreu. Meninas Perdidas: os populares e o cotidiano do amor no Rio de Janeiro da Belle Epoque. Rio de Janeiro: Editora Paz e Terra, 1989, p. 76.

${ }^{32}$ Ver OLIVEIRA, Fabiana Luci de; SILVA, Vírginia Ferreira da. "Processos judiciais como fonte de dados: poder e interpretação”. Sociologias, Porto Alegre, ano 7, n 13, jan/jun 2005, p. 244-259.

${ }^{33}$ THOMPSON; E. P. Costumes em comum, p. 346.

${ }^{34}$ Acervo da Comarca do Rio das Mortes: Laboratório de Conservação e Pesquisa Documental da UFSJ (LABDOC/UFSJ). Localização: PC 710, CX. 32. Processo criminal. 1893. Depoimento de Rosaura Maria de Jesus.
} 
Reginaldo Rafael”, assim ela é posta no levantamento de informações. ${ }^{35}$ Mesmo empreendendo estratégias como trabalho, formação familiar e busca por boa reputação após o fim da escravidão, os ex-cativos ainda defrontariam-se com desafios como a permanência de antigos estigmas sociais. ${ }^{36}$ Ainda é preciso lembrar aqui que se tratava de um momento onde as teorias científicas de cunho racial alinhavam-se a um projeto político que criava novas hierarquias entre as camadas populacionais do país. ${ }^{37}$

É claro que numa região interiorana e de pequeno porte como Oliveira, algumas designações poderiam atuar como localizadores sociais. Ser "filho de fulano de tal", "pai de beltrano", ou "membro da família X ou Y", não são frases difíceis de serem encontradas em fontes que fazem referência a cidades como essa, onde a população, em menor número, facilmente se conhecia, e assim utilizava essas nomenclaturas como aparato de identificação dos sujeitos. Sintomas também de uma região de famílias enraizadas e onde arranjos familiares demarcavam as relações de poder. A questão é que quando se escolhem os elementos de identificação, afirma-se o que é considerado como relevante socialmente em cada contexto ou local: laços familiares, por exemplo. O vínculo familiar é uma forma de localizar social, econômica e moralmente a pessoa. Quando essa identificação remete para o passado escravo, ativa a relação com o cativeiro como localizador social e moral.

Segundo o laudo do crime sofrido pela ofendida, as porretadas sofridas a ocasionaram grave ferimento na espinha dorsal e entre as espáduas. Outra lesão no antebraço esquerdo e uma no joelho esquerdo também foram notadas. A mesma se encontrava, como disse, adoentada. Por conta da idade (que não foi precisamente informada, mas observa-se nas pistas que a ex-escrava era idosa), da condição da vítima e da intensidade das lesões, a ofensa física foi considerada grave pelo júri popular.

Agora, o que realmente realça aos olhos é a perspicácia de Bárbara em responder ao seu oponente, Simião, mesmo na situação que se encontrava, acamada, e mesmo com a idade avançada. Temos aqui um exemplo de mulher que atravessou o lugar social dado a ela e desafiou um homem, mesmo na condição em que estava, e com as consequências que poderia sofrer. Sem contar que, explicitamente, me parece que o fato de as duas netas

\footnotetext{
${ }^{35}$ Acervo da Comarca do Rio das Mortes: Laboratório de Conservação e Pesquisa Documental da UFSJ (LABDOC/UFSJ). Localização: PC 710, CX. 32. Processo criminal. 1893. Auto de corpo de delito de Bárbara Francisca de Jesus.

${ }^{36}$ MATTOS, Hebe Maria; RIOS, Ana Maria Lugão. O pós-abolição como problema histórico: balanços e perspectivas. TOPOI, v. 5, n. 8, jan.-jun. 2004, pp. 170-198, p.180.

${ }^{37}$ Ver obras como SCHWARCZ, Lilia Moritz. O espetáculo das raças. Cientistas, instituições e questão racial no Brasil. 1870-1930. São Paulo: Companhia das Letras, 1993.
} 
estarem se envolvendo em relacionamentos ilícitos na ocasião, poderiam ter sido agravantes que levaram ao desapontamento e ao ato de enfrentamento da avó. Como dito por ela, já era "tarde demais" para duas moças abrirem portas e estarem recebendo rapazes em casa: a especulação quanto à moral das famílias e os comentários de vizinhos e conhecidos quanto ao comportamento feminino pesavam muito nessa época. ${ }^{38}$

Claro que casos como esse não são tão simples, e não cabe ao historiador bater o martelo final do julgamento ou tentar reconstituir os fatos exatos. Mas nesta situação específica nos parece que a questão da moral falou bem alto. Fazendo menção à análise de Martha Abreu, essas ações revelavam significados próprios acerca de honra construídos pelos segmentos populares. Por exemplo, as regras de namoro entre populares não tentavam meramente imitar ou eram os mesmos que os relacionamentos ditos como "tradicionais" das elites. ${ }^{39}$ Regras como o noivado anterior ao casamento apareciam bem menores em escala de importância nos costumes de moças pobres. ${ }^{40}$ Não quer dizer que essas relações fossem menos formais ou honrosas, mas que se organizavam em eixos bem específicos.

Para mulheres como Bárbara, que criava duas netas, o fato de representar a chefia moral e mais velha dentro de casa dizia muito. Impor ordem e defender o que se entendia como imagem simbólica de suas netas era relevante. No entendimento de seus hábitos, abrir portas para rapazes tarde da noite era uma situação que pedia interferência. A imputação, a colocação de uma mulher perante a uma situação como essa não necessariamente dependia da presença ou ausência de um companheiro. Afirmar isso seria diminuir as potencialidades de ações dessas mulheres perante a falta ou presença de uma figura masculina.

O caso durou um tempo razoavelmente extenso. Só foi finalizado em 1895, após vários despachos de juízes, interferência da Promotoria, depoimentos e até organização de um júri popular. Rosaura, Cândida, Simião, Miceno, Francisco e outros moradores do Distrito, que ouviram a confusão na noite da briga, foram chamados por pelo menos duas vezes, cada um, para depor. Simião preferiu não falar sobre o ocorrido, enquanto os outros todos confirmaram o teor de sua agressão. Ao final, Simião foi declarado culpado.

\footnotetext{
${ }^{38}$ ESTEVES, Martha de Abreu. Meninas Perdidas, p. 67. ${ }^{39}$ ESTEVES, Martha de Abreu. Meninas Perdida, p.140. ${ }^{40}$ ESTEVES, Martha de Abreu. Meninas Perdidas, p.147.
} 
O destino do caso se difere, por exemplo, de uma situação ocorrida também em Oliveira em 1904. ${ }^{41}$ Mecias Gabriella Maia dos Santos tentara separar uma confusão entre duas ex-escravas, Silvéria e Ambrozina. A vítima foi agredida com uma garrafada no rosto quando recebeu uma garrafada de Silvéria, que argumentara que a agressão fora não-intencional. Ao final do breve processo, mesmo com variados testemunhos e auto de corpo de delito, o caso é dado como improcedente.

Durante o processo, não fica muito clara a motivação da confusão entre Silvéria e Ambrozina. Uma das hipóteses que apostaríamos dizer é que a briga poderia ter sido causada por algum tipo de insulto ou comentário que levou ao desagrado de alguém. Infelizmente não poderemos confirmar tal presunção, pois neste exemplo, as principais envolvidas não depõem. A ausência de falas de mulheres novamente é notável. As únicas pessoas ouvidas são as seguintes testemunhas: Maria Rosa (lavadeira), Sebastião Moreira dos Santos, Juvêncio Almeida e Olegário Machado (ambos lavradores). Nessa situação, a fala masculina ganha maior proporção, já que o número de homens depoentes é mais significativo. Apesar da presença relevante de mulheres na cena do crime, como elucida o testemunho de Machado, apenas uma delas é requerida para prestar depoimento:

\begin{abstract}
Disse que quando passou de frente da casa de [Mecias] Gabriella dos Santos, ali estavam Silvéria, Maria de Tal, Nicesia dos Santos, Mecias e Ambrozina de Tal que foi do João Salles, que estavam alteradas todas, dizendo que deixassem de barulho, dirigindo-se sempre para sua casa, onde apareceu já noite, Mecias dizendo que Silvéria lhe atirava com uma garrafa ao rosto. Naquela ocasião, não viu os ferimentos de [Mecias] Gabriella por ser de noite e [Mecias] Gabriella ficou do lado de fora de sua casa, vendo-lhe os ferimentos depois, e já quase sãos. ${ }^{42}$
\end{abstract}

Assim como no caso anterior, o passado escravo das envolvidas é acionado, inclusive por outros populares: "Ambrozina de Tal que foi do João Salles" e " Silvéria que foi do Guilhermino" são como as duas mulheres são identificadas pelas testemunhas. Não temos certeza da origem racial dos depoentes, mas presumimos se tratarem de homens pobres, por estarem imersos naquele universo e pela ocupação de lavradores. Essa alusão ao passado cativo das rés pode inclusive, nesta situação, servir enquanto um aparato de diferenciação social, ou mesmo para transparecer velhas rixas pessoais. Assim como o comportamento poderia servir como uma maneira de demarcar as acusadas, outros estigmas poderiam ser utilizados. A "produção do criminoso" não era algo

\footnotetext{
${ }^{41}$ Acervo da Comarca do Rio das Mortes: Laboratório de Conservação e Pesquisa Documental da UFSJ (LABDOC/UFSJ). Localização: PC 1019, CX. 51. Processo Criminal. 1904.

${ }^{42}$ Acervo da Comarca do Rio das Mortes: Laboratório de Conservação e Pesquisa Documental da UFSJ (LABDOC/UFSJ). Localização: PC 1019, CX. 51. Depoimento de Olegário Machado.
} 
construído só pelas linhas do judiciário: como mencionamos de início todos os sujeitos, apesar da desigualdade de poder, podem participar, a seu modo, na construção do caso. Os demais envolvidos também podiam colaborar para a consolidação da imagem dos réus. ${ }^{43}$

Mecias Gabriella, Silvéria, Nicesia e Ambrozina foram assim, no depoimento de Olegário Machado, todas lembradas como pessoas presentes no momento da briga, mas apenas a voz de Mecias aparece na documentação, ao longo do processo. E ainda assim, a voz de Mecias surge indiretamente, já que apesar da mesma ter sido a vítima e a responsável pela denúncia, o único momento em que insurge é na queixa e no auto de corpo de delito. O grande dificultador dessas leituras criminais é exatamente esse modelo prescritivo do júri que por diversos momentos oferecia poucas oportunidades de falas a indivíduos como mulheres negras e pobres. Mas tentemos abordar o máximo de reflexões possíveis com as informações encontradas.

É importante deixarmos claras algumas percepções relevantes acerca da situação específica. É importante, de antemão, dizermos que o fato de mulheres pobres e negras estarem envolvidas em casos de agressão não as fazem mais briguentas ou enérgicas que outros indivíduos. Deve-se tomar muito cuidado ao caminhar sobre o gelo fino dos estereótipos. Como citado previamente, as ocorrências de ofensas físicas eram comuns no mundo social onde essas pessoas viviam. A violência era um constituinte cultural local, não um sinal patológico.

O crime também é revelador de como o cotidiano dessas mulheres se concebia. Independente da motivação do conflito, as envolvidas preferiram resolver ali mesmo, num ambiente público, suas pendências. Discutir publicamente não era, para estas, uma motivação de vergonha, mas sim, em suas concepções, o que era vexaminoso era deixar de requerer sua honra. E a faziam sem a interferência de uma figura masculina: na realidade é Mecias Gabriella, outra mulher, quem tenta separar a confusão e acaba levando uma "garrafada" na situação. As motivações eram variadas, mas a defesa da honra é aqui uma forte presunção que arriscaria dizer. Comentários despretensiosos (ou intencionais) sobre comportamento, relações passionais, entre outros, podiam se tornar a gota d'água para confusões como essa. Segundo Ivan Vellasco, naquela sociedade as

\footnotetext{
${ }^{43}$ CARVALHO, Leonam Maxney. Africanos e crioulos no banco dos réus: Justiça, sociedade e escravidão em Oliveira, MG, 1840-1888. 2009, 182 p. Dissertação (Mestrado em História). Universidade Federal de Minas Gerais, Faculdade de Filosofia, Ciências Sociais e História. Belo Horizonte, p. 54.
} 
pessoas eram movidas pelo compromisso com a própria imagem. ${ }^{44}$ Não seria diferente para as ex-cativas, que além de tudo, lutavam contra as marcas deixadas pelo cativeiro.

As relações entre os populares possuíam assim sua própria lógica de regras, que não deve ser lida como uma simples oposição das regras civilizadoras impostas pelas elites. ${ }^{45}$ Esses princípios básicos funcionavam num ordenamento bem autônomo, próprio das necessidades e simbologias construídas no entorno das relações sociais desses indivíduos. Portanto, olhá-los a partir do âmbito elitista é não compreender as especificidades dos seus significados.

No conflito entre Silvéria e Ambrozina, a garrafa foi o objeto utilizado para defesa - o que acabou provocando o ferimento "não-intencional” de Mecias, quando esta interferiu na briga. $O$ fato de haver uma garrafa na cena do crime não confirma a possibilidade de que as mesmas estivessem alcoolizadas ou ingerido alguma bebida que as deixassem alteradas. Mas como também não exclui a hipótese, é preciso notá-la e levála em consideração. Em Minas Gerais, um dos grandes inimigos do Estado no controle da violência era a embriaguez. ${ }^{46}$ Bebidas alcoólicas quando associadas à defesa da imagem eram assim, atenuantes consideravelmente perigosos, por acentuarem atos impulsivos. ${ }^{47}$ Desde o Código Criminal de 1831 o uso de armas de fogo é proibido e criminalizado no país. ${ }^{48} \mathrm{O}$ que reduz, mas não dizima totalmente a violência. ${ }^{49} \mathrm{Em}$ momentos "acalorados", outros objetos acabam as substituindo, como facas ou instrumentos de trabalho, por exemplo. ${ }^{50}$

Após depoimento das testemunhas e provas colhidas, o caso é dado como improcedente pelo Juiz. O tribunal chega à conclusão de que a garrafada levada por Mecias não fora dada de propósito por Silvéria. Mesmo com provas finais e testemunhos, o conflito sofre pouca interferência dos tribunais, ao contrário do caso de Bárbara.

Com isto, não afirmamos que o caráter social, racial ou de gênero fosse definitivo para delinear os fins de todos os processos julgados pelo tribunal mineiro. O que levanto aqui é o questionamento em relação à postura tomada em casos como esse último. A

\footnotetext{
${ }^{44}$ VELLASCO, Ivan de Andrade. As seduções da ordem, p.166.

${ }^{45}$ ESTEVES, Martha de Abreu. Meninas Perdidas, p.198.

${ }^{46}$ VELLASCO, Ivan de Andrade. As seduções da ordem, p. 268.

${ }^{47}$ VELLASCO, Ivan de Andrade. As seduções da ordem, p. 270.

${ }^{48}$ VELLASCO, Ivan de Andrade. As seduções da ordem, p. 275.

${ }^{49} \mathrm{Com}$ isto não quero dizer que a proibição de armas de fogo não tenha tido impacto significativo na sociedade. Na realidade, a criminalização de seu uso é prolífera, porque impede que certos atos impulsivos sejam ocasionados. Além disso, não devemos esquecer que se trata de um objeto perigosamente letal; daí a necessidade desse tipo de proibição.

${ }^{50}$ VELLASCO, Ivan de Andrade. As seduções da ordem, p.274.
} 
resolução, inclusive, incide ainda como mais intrigante, até pela presença de provas como o próprio corpo de delito.

Na situação de Mecias e Silvéria, o argumento utilizado para a descontinuidade é o caráter da não-intencionalidade. Mas vejamos: em setembro de 1912, alguns anos depois, foi registrado em Japão, distrito de Oliveira, um caso envolvendo uma confusão entre dois homens pobres, que se aproxima em alguns aspectos da briga entre as duas mulheres. O denunciado, Narvindo Marcos Velloso, estaria embriagado e acabou ferindo com um canivete a vítima Sebastião Miguel da Costa, supostamente "sem querer", ao tentar abraçá-lo. ${ }^{51}$ A ocasião também envolveria embriaguez. Mas, ao contrário da situação envolvendo as duas mulheres, o Juiz de Direito coloca que, apesar da intenção dolosa do acusado, o caso deveria ser levado à frente, e um novo processo ser aberto. Resultado: o réu foi condenado à pena de 17 dias e 12 horas de prisão simples.

Apesar do caráter não-intencional da agressão sofrida por Mecias, a reflexão que fica é a seguinte: até onde o fato de mulheres estarem no contexto de uma confusão como esta, de uma briga em público, já torna suas posturas como algo julgável e o caso como improcedente, de antemão? Até onde, na percepção dos magistrados da época, valeria a pena levar à frente e empenhar-se em um caso envolvendo mulheres negras pobres, excativas, e como agravante, supostamente embriagadas? Não queremos afirmar nenhuma conclusão acerca, mas gostaríamos de deixar esses questionamentos. Por fim, não podemos excluir a hipótese de que o caso não tenha sido levado à frente simplesmente por conta da não-intencionalidade da agressão. Mas realçamos que nem sempre as coisas são tão óbvias e simples como parecem ser.

Segundo Bóris Fausto, que analisou a criminalidade em São Paulo nos anos iniciais do século $\mathrm{XX}$, os tipos de contravenções diferenciadas revelavam quais eram as preocupações mais evidentes da Polícia do local, na imposição da ordem. ${ }^{52}$ Ao lado desse fator, existia a questão racial: havia possibilidade de mulheres negras não terem recorrido às autoridades policiais, por muitas das vezes, por conta do medo da discriminação e desqualificação, devido ao tratamento policial dado a pessoas de sua cor, gênero e posição social. $^{53}$

\footnotetext{
${ }^{51}$ Acervo da Comarca do Rio das Mortes: Laboratório de Conservação e Pesquisa Documental da UFSJ (LABDOC/UFSJ). Localização: PC 997, CX 50. Processo Criminal. 1912.

${ }^{52}$ FAUSTO, Bóris. Crime e cotidiano, p. 46.

${ }^{53}$ FAUSTO, Bóris. Crime e cotidiano, p. 71.
} 
Todavia, diferentemente dessa situação, a Justiça demonstrou alto grau de envolvimento no primeiro exemplo narrado, de Bárbara. Todas as etapas foram formalmente seguidas, e no final, por unanimidade do júri, Simião foi declarado culpado, sendo incurso no grau máximo no artigo 304, parágrafo único do Código Penal. A lei referente a lesões físicas trazia punição no caso "da lesão corporal resultar mutilação ou amputação, deformidade ou privação permanente do uso de um órgão ou membro, ou qualquer enfermidade incurável e que prive para sempre o ofendido de poder exercer o seu trabalho". ${ }^{4}$ Além disso, por estar alcoolizado na ocorrência do crime, Simião respondeu por mais este agravante, o da embriaguez. No total, pegou 11 meses, 11 dias e 6 horas de regime fechado, sendo sua prisão iniciada em 28 de junho de 1895.

Os hábitos dos envolvidos parecem ainda ter sido um ponto cheque no desenrolar da sentença. Todos os depoentes, resumidamente, disseram que Bárbara procedia "bem" e que Simião procedia "mal". Antônio Araújo acrescentou que "Bárbara usava de tomar aguardente, mas conserva-se em sua casa"; o costume de beber, nesse caso, parecia não violar a ordem pública e o comentário não representou, portanto, um peso na decisão judiciária contra sua conduta. ${ }^{55}$ Araújo também revelou em seu testemunho que ouviu um desentendimento anterior ao julgamento entre Francisco e Simião: ouviu Simião dizer a Francisco Fidélix que "hoje era dia de cobrar dele"; ao que Francisco Fidélix respondeu: "não tenho malquerença com você", Simião teria retorquido: "você não tem, mas eu tenho". Provavelmente esse relato foi um complicador na situação penal de Simião Nogueira.

Simião também teve como agravantes os fatos de Bárbara ser mais velha, a invasão do domicílio efetuada por ele e a presença e desrespeito pela enfermidade da vítima. ${ }^{56}$ Apesar da lei brasileira ter sido mais branda em relação a crimes de invasão e danos contra a propriedade do que em relação a crimes de violência, nesse caso temos a presença desses dois fatores unidos. ${ }^{57}$ Sem contar que a nova Constituição garantiria maior direito de proteção à propriedade. Em relação à diferença de força física entre o

\footnotetext{
${ }^{54}$ BRASIL. Código Penal dos Estados Unidos do Brazil. Decreto no 847 , de 11 de outubro de 1890. Artigo 304. Disponível em: $<$ https://www2.camara.leg.br/legin/fed/decret/1824-1899/decreto-847-11-outubro1890-503086-norma-pe.html>. Acesso em 22/04/2020.

${ }^{55}$ Depoimento de Antônio Symplicio Alves de Araújo.

${ }^{56}$ BRASIL. Código Penal dos Estados Unidos do Brazil. Decreto no 847, de 11 de outubro de 1890.

Parágrafos 5, 12 e 15 do Artigo 39 do Código Penal. Disponível em: $<$ https://www2.camara.leg.br/legin/fed/decret/1824-1899/decreto-847-11-outubro-1890-503086norma-pe.html>. Acesso em 22/04/2020.

${ }^{57}$ VELLASCO, Ivan de Andrade. As seduções da ordem, p. 254.
} 
acusado e Bárbara no que se refere à agressão, esta foi denominada no documento legalmente de "superioridade em sexo". ${ }^{58}$ Um termo jurídico que apesar de significar desigualdade de força física, poderia ter variadas interpretações.

Mas afinal de contas, o que difere esse caso do anterior, para que a demanda de uma ex-cativa seja aceita e seu agressor punido? Por mais que não possamos definir a resposta, e este nem seja nosso ponto principal, podemos levantar hipóteses sobre os significados. Primeiramente, os fatos explícitos já demonstram o porquê da atuação tão apurada da Justiça. Um indivíduo alcoolizado, que invade uma residência e agride uma mulher idosa. Simião, numa situação completamente infeliz, conseguiu reunir em um ato vários complicadores vistos pelo Estado como empecilhos à ordem pública. Portanto, arriscaríamos dizer que sua punição não foi apenas um mero sentenciamento como qualquer outro, mas um sentenciamento exemplar. Simião, aos olhos do júri, não feriu apenas à Bárbara. Mas causou transtornos que lesionavam a organização social. Característica da Justiça mineira da época, característica de reflexos do novo Código Penal, ambos alinhados com medidas de ordenação.

O outro ponto, que ao meu ver é implícito e não insurge em medidas legais específicas nessa situação, mas que é relevante ser lembrado, é o fator da moralização e vigilância sobre o corpo feminino. Se para Bárbara ver Rosaura e Cândida, suas netas, se envolvendo com dois homens casados era um mal pressuposto, para a jurisprudência esse tipo de relação passional poderia, por ventura, significar danos à ordenação de papéis sociais. Intervenções do Estado na esfera privada de relações refletiam no "bom funcionamento" social no âmbito público. ${ }^{59}$

Todavia, devemos lembrar da complexidade do jogo imerso nos tribunais e da heterogeneidade dos sujeitos envolvidos. Simião, o agressor, teve seu destino decidido pelo júri popular. Por mais que muitos indivíduos que constituíssem esse júri - pessoas de poder e influência regional - estivessem alinhados às regras e interesses dos magistrados da Justiça, não podemos deixar escapar que os próprios jurados poderiam analisar os casos a partir de pressupostos de moralidade local, que nem sempre caminhavam em consonância das regras da lei. ${ }^{60}$ São os agentes do Estado que batem o

\footnotetext{
${ }^{58}$ É circunstância agravante o fato de "ter o delinquente superioridade em sexo, força ou armas, de modo que o ofendido não pudesse defender-se com probabilidade de repelir a ofensa". BRASIL. Código Penal dos Estados Unidos do Brazil. Decreto $\mathrm{n}^{\circ}$ 847, de 11 de outubro de 1890. Artigo 39. Disponível em:<https://www2.camara.leg.br/legin/fed/decret/1824-1899/decreto-847-11-outubro-1890-503086norma-pe.html>. Acesso em 22/04/2020.

${ }^{59}$ ESTEVES, Martha de Abreu. Meninas Perdidas.

${ }^{60}$ RESENDE, Edna Maria. Entre a solidariedade e a violência, p. 93.
} 
martelo e definem as sentenças, mas não são os únicos a moverem o caminhar dessas histórias. Autores como Marcos Bretas nos chamam atenção para a leitura dos processos enquanto ferramentas potentes para o entendimento do cotidiano, e não somente como mecanismos de dominação estatal. ${ }^{61}$

Edward Thompson ressalta a cautela necessária em não se colocar a lei como um mero instrumento legitimador das classes dominantes. ${ }^{62}$ É claro, na visão de Thompson, que ela reforça as relações de classe existentes e amplia determinados poderes, mas não pode ser resumida a uma mera "dissimulação" da realidade com viés único de interesses, ou uma farsa. ${ }^{63}$ Ela legitima espaços e atos, mas serve também para orientar a dinâmica social e organizá-la. ${ }^{64}$ Além disso, como mencionado no início do texto e trazido por Ivan Vellasco, a Justiça mineira enraizou-se utilizando mecanismos civilizatórios próprios no enfrentamento da violência local. ${ }^{65}$ Por mais que não pudesse funcionar alheia às mudanças nacionais, o intento moralizador poderia ser reflexo de formas específicos no tratamento da Justiça de Minas aos casos criminais e valores locais, e não unicamente sintoma da implementação do Código de 1890.

Voltando a esboçar um pouco sobre o cotidiano. No processo retratado a ação de Bárbara Francisca de Jesus, ex-escrava, denota que essas mulheres tinham plena condição de liderarem moralmente os lares onde estavam incluídas. A autoridade revelada em sua postura, mesmo estando doente e mais velha, de assumir o controle da situação, envolvendo-se consequentemente numa briga, mostra a potencialidade feminina de liderança e proteção familiar.

Família e trabalho eram essenciais nas experiências de liberdade dessas mulheres. E nessa situação, ainda podemos ressaltar a importância da maternidade. Pois apesar de ser a avó, era Bárbara a responsável pela criação de Rosaura e Cândida. Essa relevância do papel materno não adveio somente com a abolição. Ao lutarem judicialmente, por exemplo, pela liberdade e tutela de seus filhos em Havana e no Rio de Janeiro, ainda durante a escravidão, muitas mulheres usaram como argumento o sentindo coletivo de família e maternidade para requerer suas ações, segundo Camillia Cowling. ${ }^{66} \mathrm{~A}$

\footnotetext{
${ }^{61}$ BRETAS, Marcos Luiz. "O crime na historiografia brasileira: Uma revisão". ANPOCS, Rio de Janeiro, n. 32,2. ${ }^{\circ}$ sem estre de 1991, pp. 49-61.

${ }^{62}$ THOMPSON, Edward Palmer. Senhores e Caçadores. A origem da Lei Negra. $2^{\text {a }}$ edição. São Paulo: Paz e Terra, 1997, p. 356.

${ }^{63}$ THOMPSON, Edward Palmer. Senhores e Caçadores, p. 357.

${ }^{64}$ THOMPSON, Edward Palmer. Senhores e Caçadores, p.351.

${ }^{65}$ VELLASCO, Ivan de Andrade. As seduções da ordem,, p. 190.

${ }^{66}$ COWLING; Camillia. Concebendo a liberdade - Mulheres de cor, gênero e a abolição da escravidão nas cidades de Havana e Rio de Janeiro. Capinas: UNICAMP, 2018, p.72.
} 
escravidão foi um grande obstáculo que impediu que muitas daquelas mulheres pudessem exercer o direito de cuidarem de seus filhos. Portanto, era necessário usar todas as estratégias possíveis para tal.

Em Minas Gerais, já no pós-abolição, laços familiares e as redes de sociabilidade foram cruciais para a organização das novas de vida, já em liberdade. ${ }^{67}$ Ter uma família era uma garantia de estabilidade e solidariedade, meios imprescindíveis para o estabelecimento das novas vivências. Podemos perceber também, a partir do caso retratado, a diversidade na composição de lares familiares. Em relação a trabalho, Cândida e Rosaura eram fiandeiras. Mesmo que não confirmado no documento, podemos supor que as mesmas receberam ensinamentos de ofício da avó. Uma forma de visualizarmos como os laços de trabalho poderiam estar cruzados aos sanguíneos.

Já no caso envolvendo Silvéria e Ambrozina, infelizmente não há informações muito precisas sobre seus perfis sociais. Podemos talvez lançar pistas sobre suas possíveis ocupações ao aproximá-las das formas de trabalho que possuíam os demais envolvidos no processo, pessoas que estavam incluídas no mesmo meio. Mecias Gabriella, a ofendida que sofreu as garrafadas, era caseira. As testemunhas, dois lavradores e uma lavadeira. Profissões ligadas ao campo - por se tratar de uma sociedade interiorana - e aos serviços domésticos e autônomos. Isso nos leva a crer que as ocupações das rés poderiam espelhar algo parecido. Os primeiros desafios de mulheres negras nos anos iniciais do pósemancipação estariam na dimensão do trabalho. Pobres e desqualificadas em grande parte, acabariam ocupando postos autônomos e de má-remuneração. Como argumentam Flávio Gomes e Olívia Cunha, "liberdade tampouco foi sinônimo de igualdade". ${ }^{68}$ Dessa forma, apesar dos textos e leis jurídicas estabelecerem um discurso igualitarista, é no cotidiano de pessoas de cor e nas relações que se estabeleceram com o pós-emancipação que encontraremos os verdadeiros e variados significados de liberdade.

Em relação a Mecias, temos outro silêncio dentro do processo. Seria ela uma mulher negra? Também uma ex-escrava? Não há menção sobre sua cor nos depoimentos. Ficaria difícil assim investigarmos se sua posição racial teria interferido ou não no prosseguimento do caso. De toda forma, o que averiguamos é que se tratou se um breve processo. Mesmo com corpo de delito e testemunhos que validaram a agressão, não houve

\footnotetext{
${ }^{67}$ RODRIGUES, João Lucas. Serra dos Pretos: Trajetórias de famílias entre o Cativeiro e a Liberdade no Sul de Minas (1811-1960). 2013, 241 p. Dissertação (Mestrado em História) Programa de Pós-graduação em História da Universidade Federal de São João del-Rei. São João del-Rei, p. 213.

${ }^{68}$ GOMES, Flávio dos Santos; CUNHA, Olívia Maria Gomes da. Quase cidadão - Histórias e Antropologias do pós-emancipação no Brasil. RJ: Editora FGV, 2007, p. 13-14.
} 
sentença. Pareceu um caso onde o comportamento da vítima importou mais que o próprio crime de ofensa física em si. Possibilidades que não podemos desconsiderar.

\section{Atuação social de mulheres negras: algumas considerações}

Por mais que a historiografia sobre o pós-abolição em Minas tenha se baseado, num primeiro momento, sobre o "mito da mineiridade", calcado numa ideia de passividade, os estudos recentes nos dão a oportunidade de ver as diversas camadas populacionais como incisivas e atuantes. Além da diversidade de projetos políticos na virada para a emancipação, mostrando que a Província não estava limitada aos desejos das elites proprietárias, os homens e mulheres de cor não estavam alheios: participaram de forma atuante, reorganizando seus novos eixos de vida em liberdade e acessando lugares como a Justiça para resolverem suas pendências pessoais.

Para visualizarmos isso melhor, precisamos expandir nossa noção de atuação e participação social. As lutas políticas lidas como legítimas não devem ser aquelas feitas somente em palacetes ou organizações formais. A ação dos diversos indivíduos naquele momento estava presente nas formas como requeriam seus direitos e também como construíram seu cotidiano.

A ausência de oportunidades de falas dadas pela Justiça à essas mulheres dizem muito sobre determinados padrões de desigualdade. Essas lacunas, na verdade, mostram que apesar dos avanços consideráveis de cidadania na Justiça e legislação no contexto do pós-emancipação, padrões de violência continuam a existir, bem como outros eram criados. Um desses padrões é o ocultamento de vozes de determinados indivíduos, entre eles, as mulheres negras.

Ainda juridicamente falando, os direitos femininos demoraram muito a serem acatados pela legislação brasileira, que ressoava vozes masculinas nos alicerces da instituição. Exemplo disto é a questão do sufrágio: mulheres só passam a votar a partir de 1932 no país. ${ }^{69}$ Ao observar os nomes dos escrivães, juízes, advogados e outros membros do campo jurídico ao longo dos processos, nota-se a presença eminentemente masculina. Portanto, torna-se entendível porque as falas e imagem dessas mulheres surgem "abafadas" e tímidas no escopo documental, num período cujas práticas de poder pautadas

\footnotetext{
${ }^{69}$ Código Eleitoral. Decreto $n^{o}$ 21.076, de 24 de fevereiro de 1932. Disponível em: < https://www2.camara.leg.br/legin/fed/decret/1930-1939/decreto-21076-24-fevereiro-1932-507583publicacaooriginal-1-pe.html> Acesso: 24/04/2020.
} 
na desigualdade de gênero eram naturalizadas e próprias do contexto. Assim, faz-se necessário o esforço do historiador em buscá-las nas entrelinhas documentais.

Os estudos de caso aqui propostos denotam um pouco das vivências de ex-cativas no período do pós-abolição em Minas Gerais, trazendo à tona conflitos em que estiveram envolvidas. A situação envolvendo Bárbara demonstra também o empenho judicial em casos onde a questão do corpo da mulher era crucial, num contexto onde medidas moralizadoras eram usuais na forma institucional de se fazer Justiça.

Ainda assim, os processos analisados mostram como a proteção da honra, o grande "pomo da discórdia”, era algo de grande relevância para esses indivíduos, advindos dos segmentos populares. A ação de avó em proteger suas netas não era mera imitação dos padrões impostos pelas elites, mas uma percepção de moral original, criada naquele seio familiar e social. Além disso, a defesa da honra estava presente em todos os segmentos sociais na sociedade interiorana retratada, lido como algo de grande importância. As excativas eram mulheres que brigavam, gritavam e batiam se necessário, para zelar por sua moral. Mas não faziam isso porque eram especialmente violentas, mas porque estavam inseridas num meio onde essa forma de resolver suas pendências era natural, entre todas as pessoas. Os processos também deixam vir à tona o desenho de seu cotidiano: relações amorosas, familiares, laços de solidariedade e desafetos pessoais.

Questões de gênero e racialidade se fazem presentes e estão intrinsicamente ligadas, ao lermos um pouco das trajetórias de mulheres negras no pós-emancipação. Questões que cada vez mais são sensíveis aos olhos de uma historiografia contemporânea que se esforça para compreender esse processo em Minas, para além de uma visão institucional. Para essas personagens, os desafios de reorganizarem suas vidas cruzavamse também aos seus conflitos pessoais, gerados a partir de situações em que para essas mulheres era necessário imputar sua própria ordem. Essas lutas fogem completamente da ideia concebida pelos nichos elitistas em torno desses sujeitos, ideias essas formadas por estereótipos de permissividade e objetificação. Desta forma, apesar dos diversos tipos de violência trazidos pelo contexto, a agência negra de atuação dessas mulheres é um sinal de como construíam suas próprias potencialidades e seus espaços possíveis de ação social.

Data de submissão: $31 / 10 / 2019$

Data de aceite: 09/04/2020 


\section{Fontes:}

a) Acervo histórico da Gazeta de Minas (antigo Gazeta de Oliveira):

- Autor desconhecido. "Coluna Echos”. Gazeta de Oliveira, Edição 549, vinte e sete de março de 1898, p. 1.

- GAMA, Carmo. "Por bem fazer, mal haver". Gazeta de Oliveira, seis de novembro de 1898, Edição 698, p. 2.

b) Acervo da Comarca do Rio das Mortes / Laboratório de Conservação e Pesquisa Documental da UFSJ (LABDOC/UFSJ):

PC 710, CX. 32. Processo criminal. 1893.

PC 1019, CX. 51. Processo Criminal. 1904.

PC 997, CX 50. Processo Criminal. 1912.

\section{Referências Bibliográficas:}

ABREU, Martha Campos. "Sobre mulatas orgulhosas e crioulos atrevidos: conflitos raciais, gênero e nação nas canções populares (Sudeste do Brasil, 1890-1920)". Tempo, $\mathrm{n}^{\mathrm{o}}$ 16, Rio de Janeiro, pp. 143-173.

ALVAREZ, Marcos César; SALLA, Fernando; SOUZA, Luiz Antônio F. "A sociedade e a lei: O Código Penal de 1890 e as novas tendências Penais na Primeira República". Justiça e História. Porto Alegre: v. 3, n. 6, 2003.

BRASIL. Código Penal dos Estados Unidos do Brazil. Disponível em: $<$ https://www2.camara.leg.br/legin/fed/decret/1824-1899/decreto-847-11-outubro1890-503086-norma-pe.html>. Acesso em 22/04/2020.

BRETAS, Marcos Luiz. "O crime na historiografia brasileira: uma revisão". ANPOCS, Rio de Janeiro, n. 32,2. ${ }^{\circ}$ sem estre de 1991, pp. 49-61.

CARVALHO, Leonam Maxney. Africanos e crioulos no banco dos réus: Justiça, sociedade e escravidão em Oliveira, MG, 1840-1888. 2009, 182 p. Dissertação (Mestrado em História). Universidade Federal de Minas Gerais, Faculdade de Filosofia, Ciências Sociais e História. Belo Horizonte.

COWLING; Camillia. Concebendo a liberdade - Mulheres de cor, gênero e a abolição da escravidão nas cidades de Havana e Rio de Janeiro. Capinas: UNICAMP, 2018. DUARTE, Eduardo de Assis. Mulheres marcadas: literatura, gênero, etnicidade. SCRIPTA, Belo Horizonte, v. 13, 2º sem, n .25, 2009, pp. 63-78.

ESTEVES, Martha de Abreu. Meninas Perdidas: os populares e o cotidiano do amor no Rio de Janeiro da Belle Epoque. Rio de Janeiro: Editora Paz e Terra, 1989. 
FAUSTO, Bóris. Crime e cotidiano: A criminalidade em São Paulo, 1880 - 1924. São Paulo: Editora Brasiliense, 1984.

GOMES, Flávio dos Santos; CUNHA, Olívia Maria Gomes da. Quase cidadão Histórias e Antropologias do pós-emancipação no Brasil. RJ: Editora FGV, 2007.

JOSÉ, Oiliam. A abolição em Minas. Belo Horizonte: Itatiaia,1962.

MATTOS, Hebe Maria; RIOS, Ana Maria Lugão. "O pós-abolição como problema histórico: balanços e perspectivas”. TOPOI, v. 5, n. 8, jan.-jun. 2004, pp. 170-198.

OLIVEIRA, Fabiana Luci de; SILVA, Vírginia Ferreira da. "Processos judiciais como fonte de dados: poder e interpretação". Sociologias, Porto Alegre, ano 7, n 13, jan/jun 2005, p. 244-259.

PRIORI, Mary Del (org.). História das Mulheres no Brasil. São Paulo: Contexto, 2004.

SCHWARCZ, Lilia Moritz. O espetáculo das raças. Cientistas, instituições e questão racial no Brasil. 1870-1930. São Paulo: Companhia das Letras, 1993.

SOBRINHO, Juliano Custódio. Sobre um tempo de incertezas: o processo de abolição e os significados de liberdade em Minas Gerais (1880-1888). 2014, 293 p. Tese (Doutorado em História). Universidade de São Paulo, Faculdade de Filosofia, Letras e Ciências Humanas. São Paulo.

RESENDE, Edna Maria. Entre a solidariedade e a violência: valores, comportamentos e a lei em São João del-Rei (1840-1860). São Paulo: Annablume, 2008.

RODRIGUES, João Lucas. Serra dos Pretos: Trajetórias de famílias entre o Cativeiro e a Liberdade no Sul de Minas (1811-1960). 2013, 241 p. Dissertação (Mestrado em História) Programa de Pós-graduação em História da Universidade Federal de São João del-Rei. São João del-Rei.

SOUZA, Cleudiza Fernandes de. O pós-abolição a partir de perspectivas de gênero e raça: processos criminais envolvendo ex-escravas em Oliveira, Minas Gerais (18901905). 2019, 179 p. Dissertação (Mestrado em História) Programa de Pós-graduação em História da Universidade Federal de São João del Rei, São João del-Rei.

THOMPSON, Edward Palmer. Costumes em comum: estudos sobre a cultura popular tradicional. São Paulo: Companhia das Letras, 1988.

THOMPSON, Edward Palmer. Senhores e Caçadores. A origem da Lei Negra. $2^{\text {a }}$ edição. São Paulo: Paz e Terra, 1997.

VELLASCO, Ivan de Andrade. As seduções da ordem: Violência, criminalidade e administração da Justiça. Minas Gerais, século 19. Bauru, SP: EDUSC. São Paulo: ANPOCS, 2004.

XAVIER, Giovana. "Entre personagens, tipologias e rótulos da 'diferença': a mulher escrava na ficção do Rio de Janeiro no século XIX”. In: GOMES, Flávio; FARIAS, 
Revista do Programa de Pós-Graduação em História da Universidade Federal do Amazonas Volume 11, número 2, out./dez. 2019.

Juliana Barreto; XAVIER, Giovana (orgs.). Mulheres negras no Brasil escravista e no pós-emancipação. São Paulo: Selo Negro, 2012. 